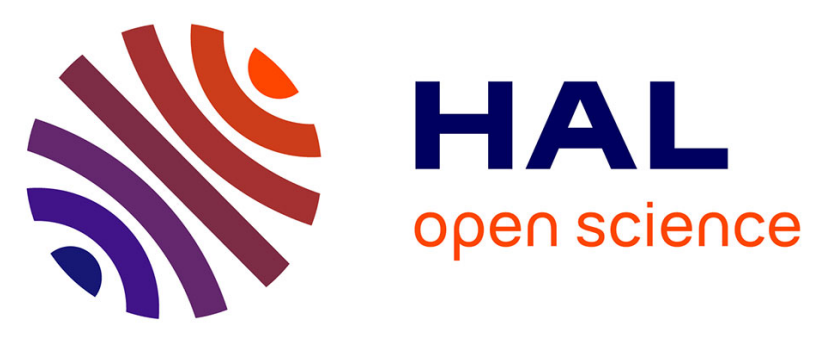

\title{
A Pilot Study of Fecal Serine-Protease Activity: A Pathophysiologic Factor in Diarrhea-Predominant Irritable Bowel Syndrome
}

Richárd Róka, András Rosztóczy, Mathilde Lévêque, Ferenc Izbéki, Ferenc

Nagy, Tamás Molnár, János Lonovics, Rafael Garcia Villar, Jean Fioramonti, Tibor Wittmann, et al.

\section{To cite this version:}

Richárd Róka, András Rosztóczy, Mathilde Lévêque, Ferenc Izbéki, Ferenc Nagy, et al.. A Pilot Study of Fecal Serine-Protease Activity: A Pathophysiologic Factor in Diarrhea-Predominant Irritable Bowel Syndrome. Clinical Gastroenterology and Hepatology, 2007, 5 (5), pp.550-555. 10.1016/j.cgh.2006.12.004 . hal-01562299

\section{HAL Id: hal-01562299 \\ https://hal.science/hal-01562299}

Submitted on 13 Jul 2017

HAL is a multi-disciplinary open access archive for the deposit and dissemination of scientific research documents, whether they are published or not. The documents may come from teaching and research institutions in France or abroad, or from public or private research centers.
L'archive ouverte pluridisciplinaire HAL, est destinée au dépôt et à la diffusion de documents scientifiques de niveau recherche, publiés ou non, émanant des établissements d'enseignement et de recherche français ou étrangers, des laboratoires publics ou privés.

\section{다(1)(2)}

Distributed under a Creative Commons Attribution - ShareAlikel 4.0 International 


\title{
A Pilot Study of Fecal Serine-Protease Activity: A Pathophysiologic Factor in Diarrhea-Predominant Irritable Bowel Syndrome
}

\author{
RICHÁRD RÓKA, ${ }^{*}$ ANDRÁS ROSZTÓCZY, ${ }^{\ddagger}$ MATHILDE LEVEQUE, ${ }^{*}$ FERENC IZBÉKI, ${ }^{\ddagger}$ FERENC NAGY, ${ }^{\ddagger}$ TAMÁS MOLNÁR, ${ }^{\ddagger}$ \\ JÁNOS LONOVICS, ${ }^{\ddagger}$ RAFAEL GARCIA-VILLAR, ${ }^{*}$ JEAN FIORAMONTI, ${ }^{*}$ TIBOR WITTMANN, ${ }^{\ddagger}$ and LIONEL BUENO* \\ *Institut National de la Recherche Agronomique, Neuro-Gastroenterology \& Nutrition Unit, Toulouse, France; and the FFirst Department of Internal Medicine, University \\ of Szeged, Szeged, Hungary
}

Background \& Aims: The pathogenesis of irritable bowel syndrome (IBS) remains only partially understood, and no specific or universally effective patient management procedure has been developed to date. Our study was designed to evaluate if colonic luminal serine-proteases may be a relevant pathophysiologic marker of IBS. Methods: Fecal samples of 38 IBS patients, 15 patients with ulcerative colitis (UC), and 15 healthy controls were studied. Fecal serine-protease activity was determined photometrically by using azocasein as a proteolytic substrate; fecal pancreatic elastase- 1 and mast cell tryptase content were measured by enzyme-linked immunosorbent assay. Fecal secretory leukocyte protease inhibitor concentration was determined by enzyme-linked immunosorbent assay in control subjects and in patients with diarrhea-predominant IBS. Results: Fecal serine-protease activity was 3 -fold higher in patients with diarrhea-predominant IBS than in both controls and IBS patients with either constipation or alternating bowel habits. Fecal serine-protease activity was not correlated with the frequency of bowel movements in all groups. Increased serine-protease activity also was detected in stools of UC patients. No significant difference was observed in the fecal mast cell tryptase and pancreatic elastase concentrations between all groups, or in the fecal secretory leukocyte protease inhibitor concentration between controls and diarrhea-predominant IBS patients. Conclusions: Fecal serine-protease activity is increased markedly in patients with diarrhea-predominant IBS. This increase, however, is not coupled with changes in either mast cell tryptase or pancreatic elastase concentrations. Thus, serine-protease activity in the colon may be a pathophysiologic factor in the development of diarrhea-predominant IBS.

$\mathrm{I}$ rritable bowel syndrome (IBS) is a chronic gastrointestinal disorder characterized by continuous or remittent abdominal pain, bloating, and altered defecation. The populationbased prevalence of IBS has been reported to be up to $28 \%$, and IBS symptoms are major reasons for primary care visits and consultations with gastroenterologists. ${ }^{1,2}$ Despite intense research, the pathogenesis of IBS remains partially understood, and no specific and universally effective patient management has been developed. Altered colonic motor function, visceral hypersensitivity, minimal inflammation of intestinal mucosa, changes in neural transmission within the gut, and alterations of sensory afferent system at spinal cord or central nervous system level may play a role in the development of IBS symptoms. $^{3}$

The gastrointestinal tract is exposed to a large array of proteolytic enzymes. Proteases are signaling molecules that regulate cell functions by cleaving proteinase-activated receptors (PARs). PARs belong to a family of 7 transmembrane-domain G-protein-coupled receptors activated by cleavage of their Nterminal domain by proteolytic enzymes. ${ }^{4}$ Four PARs have been identified: $\mathrm{PAR}_{1}, 2,3$, and 4 . In animal models, intracolonic infusion of $\mathrm{PAR}_{2}$ agonist activated spinal afferent neurons and produced a delayed rectal hyperalgesia, ${ }^{5}$ colonic $\mathrm{PAR}_{2}$ activation caused delayed facilitation of capsaicin-evoked visceral nociception, ${ }^{6}$ and activation of $\mathrm{PAR}_{2}$ in enteric nerves by mast cell tryptase caused neuronal hyperexcitability. ${ }^{7} \mathrm{PAR}_{2}$ also influenced visceral nociception by regulating intestinal permeability. Intracolonic administration of $\mathrm{PAR}_{2}$ agonist to mice increased colonic paracellular permeability by a direct myosin light chain kinase-dependent mechanism. ${ }^{8}$ Furthermore, a stress-induced increase in colonic permeability was responsible for visceral hypersensitivity. ${ }^{9}$ Thus, we can hypothesize that PARs are involved in the development of visceral hypersensitivity and subsequent IBS symptoms. PARs are highly expressed throughout the intestine, and particularly at the apical site of colonocytes. ${ }^{10}$ Moreover, proteolytic enzymes from both endogenous and exogenous origins are present at high concentrations in the gut. ${ }^{11,12} \mathrm{~A}$ recent preliminary work showed an increased trypsinlike proteolytic activity in colonic biopsy specimens from IBS patients. ${ }^{13}$

Therefore, the present study aimed to evaluate the following: (1) whether colonic luminal proteases are increased in IBS patients, as reflected by stool analysis, and, (2) the possible origin, endogenous (mast cell, pancreas) and/or exogenous (luminal content), of luminal serine-proteases, which may interact with $\mathrm{PAR}_{2}$ located at the apical site of mucosal epithelial cells.

Abbreviations used in this paper: IBS, irritable bowel syndrome; IBS-A, irritable bowel syndrome with alternating habits; IBS-C, constipation-predominant irritable bowel syndrome; IBS-D, diarrhea-predominant irritable bowel syndrome; PAR, proteinase-activated receptor; SLPI, secretory leukocyte protease inhibitor; UC, ulcerative colitis.

$$
\begin{gathered}
\text { ㄷ) } 2007 \text { by the AGA Institute } \\
1542-3565 / 07 / \$ 32.00 \\
\text { doi:10.1016/j.cgh.2006.12.004 }
\end{gathered}
$$


Table 1. Demographic Data, Intensity of Pain and Bloating, and Stool Consistency in IBS Groups Studied

\begin{tabular}{|c|c|c|c|c|c|c|}
\hline \multirow[b]{2}{*}{ Groups } & \multirow[b]{2}{*}{ Age, $y$} & \multicolumn{2}{|c|}{ Sex } & \multirow{2}{*}{$\begin{array}{c}\text { Abdominal pain, } \\
\text { VAS } \%, \text { mean } \pm \text { SEM }\end{array}$} & \multirow{2}{*}{$\begin{array}{c}\text { Bloating, } \\
\text { VAS } \%, \text { mean } \pm \text { SEM }\end{array}$} & \multirow{2}{*}{$\begin{array}{l}\text { Stool consistency, } \\
\text { Bristol }(1-7), \text { mean } \pm \text { SEM }\end{array}$} \\
\hline & & Women & Men & & & \\
\hline IBS-C & $29-37$ & 13 & 1. & $47.7 \pm 7.9$ & $56.6 \pm 7.5$ & $2.5 \pm 0.6$ \\
\hline IBS-A & $45-69$ & 5 & 2 & $50.0 \pm 10.8$ & $53.7 \pm 20.7$ & $5.2 \pm 0.7$ \\
\hline |BS-D & $20-75$ & 14 & 3 & $56.6 \pm 6.7$ & $48.3 \pm 7.3$ & $5.6 \pm 0.4$ \\
\hline
\end{tabular}

NOTE. Pain intensity was evaluated by a visual analogue scale (VAS) and stool consistency was evaluated by the Bristol scaie. Studied groups included the following: IBS-C, IBS-A, and IBS-D patients.

\section{Methods}

\section{Patients}

Thirty-eight patients with IBS fulfilling the Rome II criteria participated in the study (age, 24-75 y; mean, $48 \mathrm{y} ; 31$ women, 7 men). Seventeen patients had diarrhea-predominant IBS (IBS-D), 14 had constipation-predominant IBS (IBS-C), and 7 had altetnating bowel habits (IBS-A) (Table 1). Organic gastrointestinal disorders were excluded by detailed blood and stool analyses, serologic assays for celiac disease, lactose-hydrogen breath test, and colonoscopy. Fifteen patients with clinically and endoscopically active ulcerative colitis (UC) also were entolled (age, 18-79 y; mean, 38 y; 10 women, 5 men), and 15 gastrointestinal symptom-free subjects were included as controls (age, 30-65 y; mean, $46 y ; 12$ women, 3 men). In addition, 5 subjects with acute infectious diarrhea (age, 69-85 y; mean, $72 \mathrm{y} ; 4$ women, 1 man) were investigated.

The study was approved by the Bthical Committee of the University of Szeged. All participants gave informed consent.

\section{Procedures}

Sample preparation. Stools from IBS patients, UC patients, and healthy controls were studied. Samples were collected and transported within 1 hour after defecation to the First Department of Medicine in Szeged, Hungary, frozen on arrival, and stored at $-20^{\circ} \mathrm{C}$. After recollection of the entire set for the study, frozen samples were shipped in dry ice to the Institut National de la Recherche Agronomique in Toulouse, France, for assays.

On arrival, stool samples were thawed at $4^{\circ} \mathrm{C}$. One spot (1-2 g) from each stool sample was collected, transferred to $4 \mathrm{~mL}$ of reaction buffer containing $0.15 \mathrm{~mol} / \mathrm{L} \mathrm{NaCl}$ and $20 \mathrm{mmol} / \mathrm{L}$ Tris- $\mathrm{HCl}$, and homogenized. Coarse particles were removed from this solution by filtration with a $0.8-\mu \mathrm{m}$ size syringe filter (Nalgene; Nalge, New York, NY) after centrifugation at 4500 rpm for 10 minutes at $4^{\circ} \mathrm{C}$. Supernatants were used for serineprotease activity and mast cell tryptase assays. For the assay of elastase, fecal proteases were extracted using sample preparation tubes (Quick-Ptep; Schebo-Tech, Giessen, Germany).

Serine protease activity assay. Aliquots $(25 \mu \mathrm{L})$ of supernatants of fecal homogenates were incubated with $1 \mathrm{~mL}$ of reaction buffer and $1 \mathrm{~mL}$ of $0.5 \%$ (wt/vol) azocasein (Sigma, St. Quentin, France) at $40^{\circ} \mathrm{C}$ for 20 minutes. The reaction was stopped by adding $1 \mathrm{~mL} 10 \%$ (vol/vol) trichloroacetic acid (Sigma). After centrifugation at $4500 \mathrm{rpm}$ for 10 minutes at $4^{\circ} \mathrm{C}$, absorption of the clear supernatant was measured at 366 $\mathrm{nm}$ and compared with standard curves obtained from a titration series of azocasein. Protein concentration of the filtered supernatant of colonic content was assessed with the BCA-200
Protein Assay Kit (Pierce, Rockford, IL), with bovine serum albumin as a standard. Serine-protease activity was expressed as units of trypsin activity per mg of protein. Two different serineprotease inhibitors (aprotinin and soybean tryptase inhibitor) were used to confirm assay specificity.

Mast cell tryptase activity. Aliquots $(10 \mu \mathrm{L})$ of supernatants of fecal homogenates were added to $200 \mu \mathrm{L}$ of buffer $(50 \mathrm{mmol} / \mathrm{L}$ Tris-HCl, pH 7.6, $120 \mathrm{mmol} / \mathrm{L} \mathrm{NaCl}, 20$ $\mu \mathrm{g} / \mathrm{L}$ heparin) containing $0.5 \mathrm{mmol} / \mathrm{L}$ substrate of mast cell tryptase (tosyl-glycine-proline-arginine-pNitroanilide) and incubated at toom temperature for 17 hours. Substrate cleavage was measured using a microplate reader (absorbance, $415 \mathrm{~nm}$ ) and normalized to the protein content of the supernatant. Concentrations were calculated automatically in comparison with a standard curve. A specific mast cell tryptase inhibitor (nafamostat mesylate) was used to confirm assay specificity.

Pancreatic elastase-1. Pancreatic elastase-1 was assayed immunologically by enzyme-linked immunosorbent assay (Schebo-Tech, Giessen, Germany) using a monoclonal antibody. against specific epitopes of human pancreatic elastase. The antigen-antibody complex was revealed by adding a conjugate peroxidase/streptavidin that binds the biotinylated antibody. The concentration of oxidized $2,2^{\prime}$-azoni-bis-3-ethylbenzothiazolin-6-sulphonic acid, a peroxidase substrate, was determined by spectrophotometry in a microplate reader at $405 \mathrm{~nm}$ as the reference wavelength. Concentrations were calculated automatically in comparison with a standard curve.

Secretory leukocyte protease inhibitor. Human secretory leukocyte protease inhibitor (SLPI) was measured immunologically by an enzyme-linked immunosorbent assay (R\&D Systems, Minneapolis; MN) using a monoclonal antibody against specific epitopes of human SLPI. The antigenantibody complex was revealed by adding a conjugated horseradish peroxidase that binds the antibody. The concentration of oxidized chromogen (tetramethylbenzidine), a peroxidase substrate, was determined by spectrophotometry in a microplate reader at $450 \mathrm{~nm}$ as the reference wavelength. Concentrations were calculated automatically in comparison with a standard curve.

\section{Statistics}

Data are presented as means $\pm S E M$. Analyses were performed by running GraphPad Prism 4.0 software (GraphPad, San Diego, CA). Multiple comparisons within groups were performed by repeated-measures 1-way analysis of variance, followed by the Kruskal-Wallis test. Correlations were analyzed using the Spearman rank correlation test. Statistical significance was accepted at a $P$ value of less than .05 . 


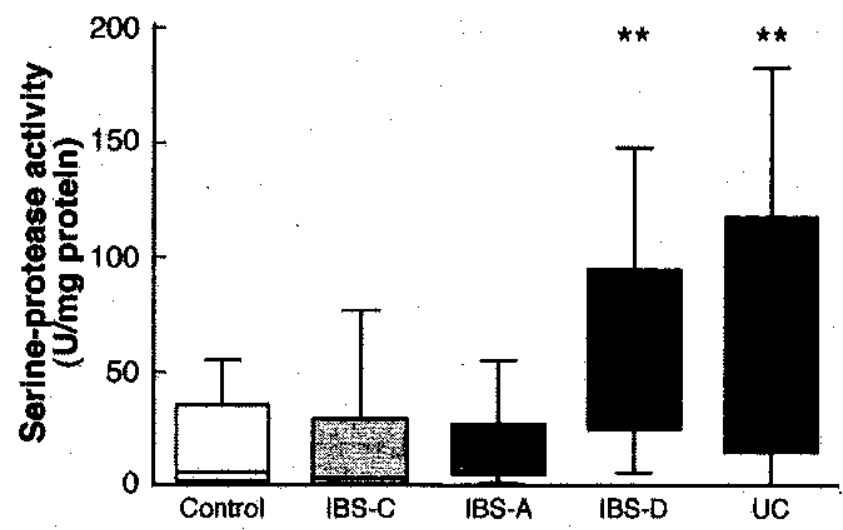

Figure 1. Fecal serine-protease activity in healthy controls, IBS-C, IBS-A, IBS-D, and UC patients, Boxes extend from the 25th-75th percentiles, lines at the median show the 50th percentile; the whiskers extending above and below the boxes show the highest and lowest values. ${ }^{* *} P<.00$ t compared with controls.

\section{Results}

In controls, the fecal setine-protease activity was $16.4 \pm$ $5.0 \mathrm{U} / \mathrm{mg}$ protein, and presented a normal distribution without apparent gender difference. In the IBS patients, the statistical analysis indicated that serine-protease activity values were not distributed normally, which lead us to consider the presence of distinct populations of IBS patients. Thus, a subgroup analysis was performed, taking into account the Rome II criteria (ie, IBS-C, IBS-D, and IBS-A), and significant subgroup differences were shown. Indeed, fecal serine-protease activity was significantly greater $(P<.001)$ in IBS-D patients $(67.9 \pm 10.8 \mathrm{U} / \mathrm{mg}$ protein) and UC patients $(67.4 \pm 15.3 \mathrm{U} / \mathrm{mg}$ protein), than in controls, IBS-C patients (16.0 $\pm 7.0 \mathrm{U} / \mathrm{mg}$ protein), and IBS-A patients (16.4 $\pm 7.1 \mathrm{U} / \mathrm{mg}$ protein) (Figure 1 ).

Fecal serine-protease activity was not correlated with the frequency of bowel movements in any of the studied groups of patients (Table 2).

No significant difference was observed in fecal mast cell tryptase activity (Figure 2) or pancreatic elastase-1 concentration (Figure 3) between any IBS subgroup, UC patients, and controls.

In addition, no significant difference was found in fecal SLPI concentrations between IBS-D patients and controls (Figure 4).

Table 2. Lack of Correlation Between Fecal Serine-Protease Activity and Frequency of Bowel Movements in the Different Groups Studied

\begin{tabular}{lccccc}
\hline Groups & $\begin{array}{c}\text { Fecal } \\
\text { senne-protease } \\
\text { level, U/mg proteln }\end{array}$ & $\begin{array}{c}\text { Bowel } \\
\text { movements/wk, } \\
\text { mean } \pm \text { SEM }\end{array}$ & \multicolumn{2}{c}{$\begin{array}{c}\text { Correlation } \\
\text { analysis } \\
\text { parameters }\end{array}$} \\
\hline Control & $16.4 \pm 5.0$ & $6.86 \pm .09$ & -0.17 & .54 \\
IBS-C & $16.0 \pm 7.0$ & $1.46 \pm .14$ & 0.10 & .73 \\
IBS-A & $16.4 \pm 7.1$ & $6.71 \pm .28$ & 0.12 & .78 \\
IBS-D & $67.9 \pm 10.8$ & $23.88 \pm 3.77$ & 0.15 & .55 \\
UC & $67.4 \pm 15.3$ & $23.40 \pm 4.54$ & 0.28 & .30 \\
\hline
\end{tabular}

NOTE. The following groups were included in the study: healthy controls, IBS-C, IBS-A, IBS-D, and UC patients.

$r$, correlation coefficient; $P$, statistics.

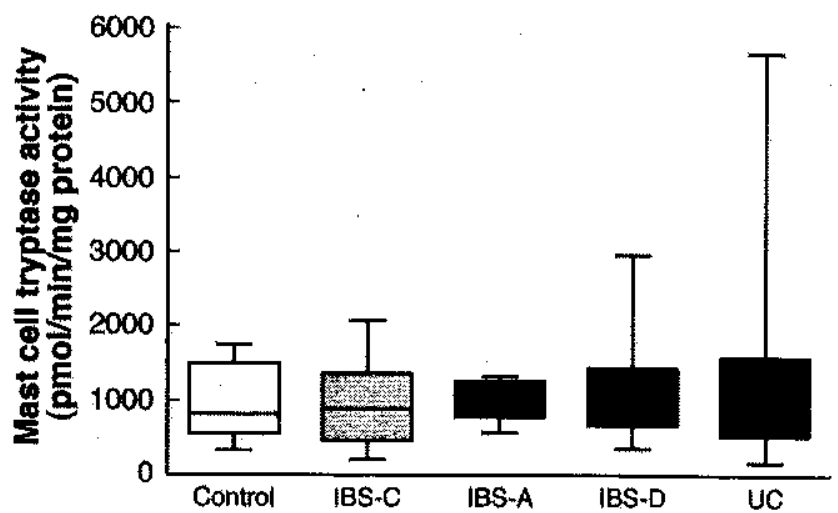

Figure 2. Fecal mast cell tryptase activity. See Figure $\dagger$ for a description of the groups. Boxes extend from the 25 th-75th percentiles, lines at the median show the 50th percentile; the whiskers extending above and below the boxes show the highest and lowest values.

No detectable serine protease activity was observed in the fecal samples of patients with acute infectious diarrhea, therefore no additional enzyme content and activity measurements were performed in this group of patients.

\section{Discussion}

The present study showed that serine-protease activity is increased markedly in stools of IBS-D patients, and that this increased fecal protease activity is not associated with increased fecal mast cell tryptase activity or pancreatic elastase-1 concentration. Similarly, increased serine-protease activity was found in patients with active UC. Our data also revealed that fecal serine-protease activity does not correlate with the frequency of bowel movements in all groups of patients.

Thus, the gastrointestinal tract is exposed to a large array of serine proteases, cysteine proteases, and metalloproteases. Trypsin and trypsinogen released from digestive glands and epithelial cells, factors from the coagulation cascade, proteases released from inflammatory cells, and bacteria are present in great amounts in the gut, particularly in the colon. ${ }^{11,12}$ Increased luminal proteases can directly break the mucus barrier, digest the underlying epithelium, and, subsequently, produce mucosal

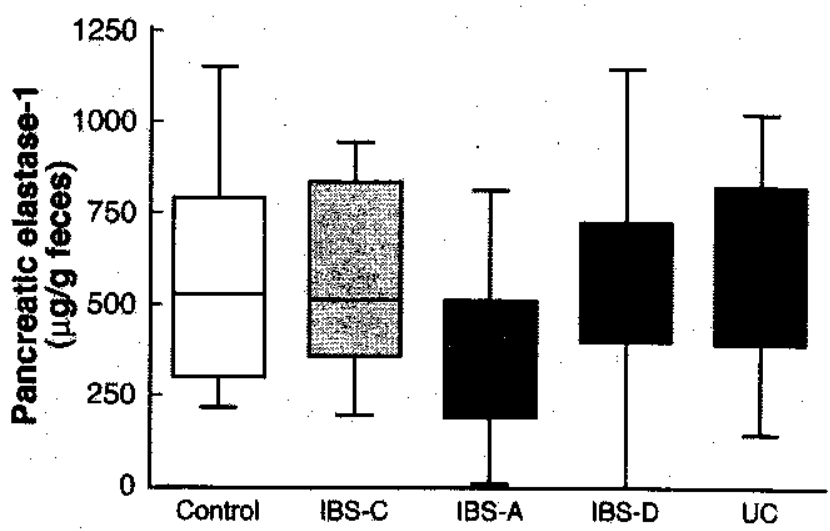

Figure 3. Fecal pancreatic elastase- 1 concentration. See Figure 1 for a description of the groups. Boxes extend from the 25th-75th percentiles, lines at the median show the 50th percentile; the whiskers extending above and below the boxes show the highest and lowest values. 


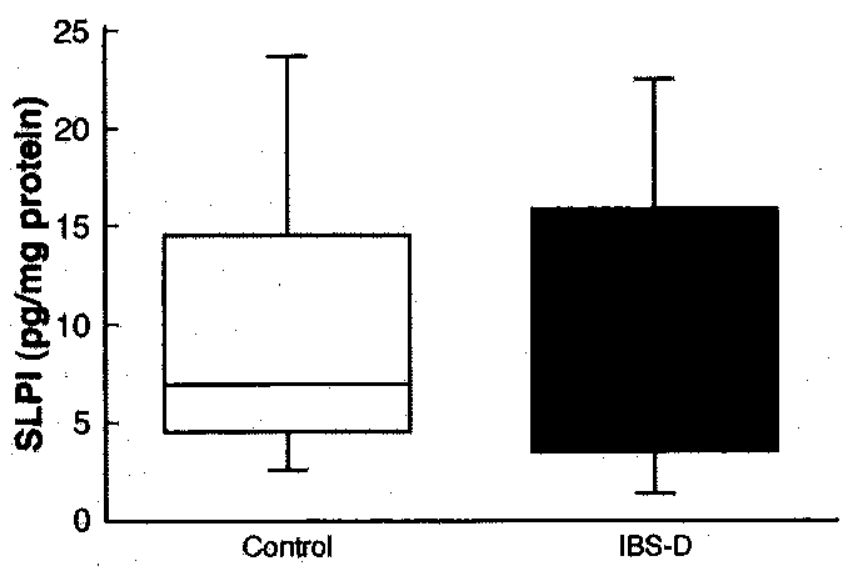

Figure 4. Fecal human SLPI concentration. See Figure $\uparrow$ for a description of the groups. Boxes extend from the 25th-75th percentiles, lines at the median show the 50th percentile; the whiskers extending above and below the boxes show the highest and lowest values.

inflammation and damage. In addition to their digestive role, proteases are signaling molecules that regulate cell functions by cleaving PARs, which are highly expressed throughout the gastrointestinal tract. These receptors are present, among others, in colonic epithelial cells, and are particularly dense at the apical site. ${ }^{13}$ In rats, intracolonic but not systemic infusion of a $\mathrm{PAR}_{2}$ agonist produced delayed rectal hyperalgesia. ${ }^{5}$ In mice, colonic $\mathrm{PAR}_{2}$ activation caused delayed facilitation of capsaicinevoked visceral nociception. ${ }^{6}$ In guinea pigs, activation by mast cell tryptase of $\mathrm{PAR}_{2}$ located at the enteric nerves caused neuronal hyperexcitability. ${ }^{7}$

$\mathrm{PAR}_{2}$ could provoke visceral hypersensitivity not only by direct action, but also indirectly by increasing colonic permeability. Thus, intracolonic administration of $\mathrm{PAR}_{2}$ agonist to mice increased the colonic paracellular permeability by a direct myosin light chain kinase-dependent mechanism. ${ }^{8}$ Moreover, an increase in colonic paracellular permeability induced by acute stress in rats is responsible for concomitant rectal hypersensitivity to distension. ${ }^{9}$ Increased intestinal permeability was found to be an important factor in the development of symptoms in patients with postinfectious $\mathrm{IBS}^{14}$ or in patients presenting with other types of IBS, ${ }^{15}$ particularly for IBS-D patients and at the colonic level. ${ }^{16}$ Recently, a preliminary study showed an increased trypsin-like proteolytic activity in colonic biopsy specimens from IBS patients. This protease activity was able to cause hyperalgesia when injected into mouse paws through a mechanism involving $\mathrm{PAR}_{2}$ activation. ${ }^{13}$ Our study showed that an increased fecal serine-protease activity is characteristic in IBS-D patients, and we suggest that this enhanced protease activity may be a pathogenic factor either by a direct action or, more probably, through $\mathrm{PAR}_{2}$ activation.

There is recent evidence for an important tole of colonic mucosal microinflammation in the pathogenesis of IBS. IBS symptoms are common in patients in remission from $\mathrm{UC}^{17}$ and in those who have had a gastrointestinal infection. ${ }^{18,19}$ An increased number of inflammatory cells is characteristic in the colonic mucosa of IBS patients. ${ }^{14,20-23}$ Because microinflammatory alterations of the colonic mucosa have been reported in IBS patients, we compared their fecal protease contents with that of UC patients who had macroscopically evident colonic inflammation. We observed similarly increased fecal serine-pro- tease activities in patients with UC and in patients with IBS-D as a possible marker of colonic microinflammation in IBS patients.

Our finding supports the results of earlier clinical studies concerning colonic protease activity and inflammatory bowel disease. Thus, fecal proteolytic activity, $\alpha$-1-antitrypsin, and neutrophil elastase were increased in patients with UC; however, only the correlation between proteolytic activity and severity of disease was significant. ${ }^{24}$ Patients with an acute attack of UC had higher levels of casein digestion, pancreatic elastase, and granulocytic elastase in fecal samples than both quiescent disease patients and controls. ${ }^{25}$ There also is growing evidence in favor not only of a direct pathogenic role of proteases, but also for a role of PARs in inflammatory bowel disease. $\mathrm{PAR}_{2}$ and tumor necrosis factor- $\alpha$ proteins are more expressed in UC tissues than in normal tissues. Most of the PAR $_{2}$-positive cells are tryptase-positive mast cells. ${ }^{26}$ In vivo, intracolonic activation of $\mathrm{PAR}_{2}$ in mice provoked colonic inflammation, at least partly mediated by an increased paracellular permeability leading to bacterial translocation into peritoneal organs. ${ }^{8,10}$ Our results agree with previous observations indicating that colonic serineprotease activity had a role in the development of inflammation in UC. According to recent obsetvations concerning PAR expression in inflammatory bowel disease, it is tempting to hypothesize that PARs participate in the genesis and severity of colonic inflammation.

It is well established that colonic resident bacteria release considerable amounts of serine proteases, cysteine proteases, and metalloproteases, and that digestive enzymes are partly degraded by host proteases and bacterial peptide hydrolases in the colon. ${ }^{27}$ Therefore, fecal proteolytic activity is influenced by the duration of colonic transit, which was confirmed in a clinical study in Crohn's disease patients. ${ }^{28}$ It can be speculated that colonic transit time could influence fecal protease activity by modifying the exposure of different luminal proteases to bacterial degradation. However; we were unable to find any correlation between serine-protease activity and frequency of bowel movements in all subgroups of IBS patients. Moreover, we failed to detect serine-protease activity in feces of patients with acute infectious diarrhea. Therefore, we can speculate that the increased fecal protease activity was the cause rather than the result of frequent bowel movements in patients with IBS-D. Furthermore, the role of luminal proteases in the development of symptoms was observed only in patients with IBS-D, and not in patients with IBS.C. This phenomenon could be explained by the heterogeneity of IBS patients and the involvement of different pathologic pathways in different types of IBS. Similar heterogeneity exists in the possible role of microinflammation in the development of symptoms. Increased numbers of inflammatory cells also were found in subgroups of IBS patients, particularly in postinfectious IBS, whereas marked differences in colonic inflammatory cell infiltration were observed between IBS-C and IBS-D patients. ${ }^{21}$

The origin of the increased protease activity in stool of IBS patients has not yet been identified because we have not observed any change in mast cell tryptase activity and pancreatic digestive enzyme concentration in fecal samples of these patients. It has been reported that pathologic changes in colonic microflora may be characteristic in IBS patients. ${ }^{29,30}$ Because colonic bacteria release proteases, we can speculate that perturbed bacterial flora may be one of the sources of increased 
fecal protease activity. It also has been shown that incteased neutrophil elastase levels were partly responsible for increased fecal proteolytic activity in UC patients. ${ }^{24}$ According to the increasing evidence of microinflammation in IBS, proteases released by inflammatory cells, except mast cells, also may be responsible for increased fecal levels of serine-protease activity.

A physiologic balance exists between proteases and protease inhibitors, which prevents the proteolytic injury of colonic mucosa in healthy conditions. ${ }^{31}$ SLPI, an antiprotease with potent inhibitory effects on human trypsin, leukocyte elastase, and mast cell chymase, can be found in biopsy specimens from human colonic mucosa and in human intestinal epithelial cell lines. ${ }^{31,32}$ Because we found an increased fecal serine-protease activity in IBS-D, we investigated the possible role of SLPI in the disturbance of the protease/antiprotease balance in this group of patients. We confirmed that the increase in serine-protease activity in IBS-D patients was not related to changes in the luminal concentration of this proteinase inhibitory factor. This observation underlines a potentially major role of colonic bacterial flora or inflammatory cells in the overproduction of fecal serine-proteases in IBS-D patients.

The possible involvement of increased luminal proteases in the development of symptoms raises the possible use of protease inhibitors in the treatment of IBS. Thus, potato protein extracts containing protease inhibitors almost completely suppressed proteolytic activity in feces, and have been successfully applied topically in protease-induced dermatitis. ${ }^{28}$ Camostat, a serine-protease inhibitor, improved reflux esophagitis after gastrectom ${ }^{33}$ and, in a pilot study, induced and maintained remission in UC patients. ${ }^{34}$ These protease inhibitors are used safely in clinical practice and could represent new agents for IBS therapy, particularly IBS-D patients.

In summary, because our pilot study showed that fecal serineprotease activity is increased markedly in IBS-D patients, we suggest that colonic luminal protease activity may be a major pathophysiologic factor in the development of IBS.

\section{References}

1. Corazziari E. Definition and epidemiology of functional gastrointestinal disorders. Best Pract Res Clin Gastroenterol 2004;18: 613-631.

2. Drossmann DA, Whitehead WE, Camillieri M. Irritable bowel syndrome: technical review for practice guideline development. Gastroenterology 1997;112:2120-2137.

3. Talley NJ, Spiller R. Irritable bowel syndrome: a little understood organic bowel disease? Lancet 2002;360:555-564.

4. Nystedt $S$, Lanson AK, Aberg $H$, et al. The mouse proteinaseactivated receptor-2 cDNA and gene. Molecular cloning and functional expression. J Biol Chem 1995;270:5950-5955.

5. Coelho AM, Vergnolle N, Guiard B, et al. Proteinases and proteinase-activated receptor 2 : a possible role to promote visceral hyperaigesia in rats. Gastroenterology 2002;122:1035-1047.

6. Kawao N, Ikeda H, Kitano $\mathrm{T}$, et al. Modulation of capsaicinevoked visceral pain and referred hyperalgesia by protease-activated receptors 1 and 2. J Pharmacol Sci 2004;94:277-285.

7. Reed DE, Barajas-Lopez C, Cottrell G, et al. Mast cell tryptase and proteinase-activated receptor 2 induce hyperexcitability of guineapig submucosal neurons. J Physiol 2003;547:531-542.

8. Cenac N, Chin AC, Garcia Villar R, et al. PAR2 activation alters colonic paracellular permeability in mice via IFN-y dependent and -independent pathways. J Physiol 2004;558:913-925.

9. Alt-Belgnaoui A, Bradesi S, Fioramonti J, et al. Acute stressinduced hypersensitivity to colonic distension depends upon in- crease in paracellular permeability: role of myosin Ilght chain kinase. Pain 2005;113:141-147.

10. Cenac N, Coelho AM, N'guyen $C$, et al. Induction of intestinal inflammation in mouse by actlvation of proteinase-activated re ceptor-2. Am J Pathol 2002;161:1903-1915.

11. Bohm SK, Kong $W$, Bromme $D$, et al. Molecular cloning, expres sion and potential functions of the human proteinase-activated receptor-2. Biochem J 1996;314:1009-1016.

12. Vergnolle $N$. Modulation of visceral pain and inflammation by protease-activated receptors. Br J Pharmacoi 2004;141:12641274.

13. Vergnolle N, Shhaffer E, Andrews C. Role for proteases and protease-activated receptor-2 in hyperalagaesia induced by supernatants of IBS patients biopsies. Neurogastroenterol Motil 2004;16:848A.

14. Spiller RC, Jenkins D, Thomley JP, et al. Increased rectal mucosal endocrine cells, T lymphocytes, and increased gut permeablity following acute Campylobacter enteritis and in post-dysenteric Irritable bowel syndrome. Gut 2000;47:804-811.

15. Marshall JK, Thabane M, Garg AX, et al. Intestinal permeability in patients with irritable bowel syndrome after a waterborne outbreak of acute gastroenteritis in Walkerton, Ontario. Aliment Pharmacol Ther 2004;20:1317-1322.

16. Dunlop SP, Hebden J, Perklns A, et al. Abnormal intestinal permeability in subtypes of diarthoea predominant IBS. Neurogastroenterol Motil 2002;14:586p.

17. Isgar B, Herman M, Kaye MD, et al. Symptoms of irritable bowel syndrome in ulcerative colitis in remission. Gut 1983;24:190192.

18. Gwee KA, Graham JC, McKendrick MW, et al. Psychometris scores and persistence of irritable bowel after infectious diarrhoea. Lancet 1996;347:150-153.

19. Neal KR, Hebden J, Spiller R. Prevalence of gastrointestinal symptoms six months after bacterial gastroenteritis and risk factors for development of irritable bowel syndrome: postal survey of patients. BMJ 1997;314:779-782.

20. Dunlop SP, Jenkins D, Nela KR, et al. Relative importance of enterochromaffin cell hyperplasia, anxiety, and depression in postinfectious IBS. Gastroenterology 2003;125:1651-1659.

21. Chadwick VS, Chen W, Shu D, et al. Activation of the mucosal immune system in irritable bowel syndrome. Gastroenterology 2002;122:1778-1783.

22. Dong WZ, Zou DW, LI ZS, et al. Study of visceral hypersensitivity in Irritable bowel syndrome. Chin J Dig Dis 2004;5:103-109.

23. Barbara G, Stanghellini V, De Giorgio R, et al. Activated mast cells in proximity to colonic nerves correlate with abdominat pain in iritable bowel syndrome. Gastroenterology 2004;126:693702.

24. Bustos D, Negri G, De Paula JA, et al. Colonic proteinases: increased activity in patients with ulcerative colitis. Medicina (B Aires) 1998;58:262-264.

25. Bohe M. Pancreatic and granulocytic endoproteases in faecal extracts from patients with active ulcerative colitis. Scand J Gastroenterol 1987;22:59-64.

26. Kim JA, Choi SC, Yun KJ, et al. Expression of protease-activated receptor-2 in ulcerative colitis. Inflamm Bowel Dis 2003;9:224229.

27. Macfarlane GT, Allison C, Gibson SA, et al. Contribution of the microflora to proteolysis in the human large intestine. J Appl Bacteriol 1988;64:37-46,

28. Ruseler-van Embden JGH, van Lieshout LMC, Smits SA, et al. Potato tuber proteins efficiently inhibit human faecal proteolytic activity: implication for treatment of peri-anal dermatit/s. Eur J Clin Invest 2004;34:303-311.

29. Balsari A, Ceccarelli A, Dubinl F, et al. The fecal microbiat population in the irritable bowel syndrome. Microbiologica 1982;5: 185-194. 
30. Swidsinski A, Khilkin M, Orthner M. Alteration of bacterial concentration in colonic biopsies from patients with irritable bowel syndrome (IBS). Gastroenterology 1999;116:A1.

31. Si-Tahar M, Merlin D, Sitaraman S, et al. Constitutive and regulated secretion of secretory leukocyte proteinase inhibitor by human intestinal epithelial cells. Gastroenterology 2000;118: 1061-1071.

32. Nystrom $M$, Westin UP, Linder $C$, et al. Secretory leukocyte protease inhibitor in punch biopsies from human colonic mucosa. Mediators Inflamm 2001;10:269-272.

33. Kono $K$, Takahashi A, Sugai $H$, et al. Oral trypsin inhibitor can improve reflux esophagitis after distal gastrectomy concomitant with decreased trypsin activity. Am J Surg 2005;190:412-417.
34. Senda S, Fujiyama $Y$, Bamba $T$, et al. Treatment of ulcerative colitis with camostat mesilate, a serine protease inhibitor. intem Med 1993;32:350-354.

Address requests for reprints to: Dr Lionel Bueno, Institut National de la Recherche Agronomique, Neuro-Gastroenterology \& Nutrition Unit, 180 Chemin de Tournefeuilie, BP 3, 31931 Toulouse Cedex 9, France. e-mail: ibueno@toulouse.inra.fr; fax: (33) 561-28-5145.

Supported by a postdoctoral fellowsh!p from the Institut National de la Recherche Agronomique (R.R.).

R.R. and A.R. contributed equally to this study. 